\title{
The influence of non-cooled exhaust gas recirculation on the indicator diagrams and heat release parameters in diesel engine cylinder
}

This paper presents the results of the diesel engine research on the indicator and heat realized diagrams for VW 1.9 TDI working in 2 modes: with standard, non-cooled EGR system, and without this system. All of measurement was carried out on the some engine speed - $2000 \mathrm{rpm}$ (speed of maximum engine torque) and various engine load. Some of the analyzed parameters were read directly from the measurement systems (e.g. indicator diagrams) or engine controller (e.g. start of injection) and the rest of them had to be calculated. The calculation of rate of heat release $(\delta Q / d \alpha)$ was based on the well-known mathematical model. When the exhaust gas recirculation valve is open, the maximum of combustion pressure and rate of maximum kinetic heat release $\left(\delta Q_{k} / d \alpha\right)_{\max }$ are smaller than when the valve is closed. These facts are connected with the shorter self-combustion delay for engine working with EGR. But this is also associated with reduction of the rate of maximum diffusion heat release $\left(\delta Q_{d} / d \alpha\right)_{\max }$, which means that more particulates $(P M)$ are excreted into the atmosphere. This fact explains e.g. significantly higher smog of exhaust gases for diesel engine which works with EGR system. The analysis results show that exhaust gas recirculation system slightly deteriorates the energetic parameters of VW 1.9 TDI engine, but, at the same time, significantly reduces the level of toxic nitrogen oxides in exhaust gases.

Key words: diesel engine, exhaust gases, EGR, indicator diagrams, rate of heat release

\section{Introduction}

This article is a continuation of the article CE-2017-446, which analyzed the influence of non-cooled exhaust gas recirculation on the diesel engine parameters. Tested Diesel engine VW 1.9 TDI worked in two operating modes:

- MODE I - with factory preset of EGR

- MODE II - without exhaust gas recirculation (EGR)

Data shown in Fig. 1 corresponds to the operation of the engine according to MODE I - factory setting of EGR. In MODE II, the percentage of opening of the EGR valve is $0 \%$ for all of range of engine torque.

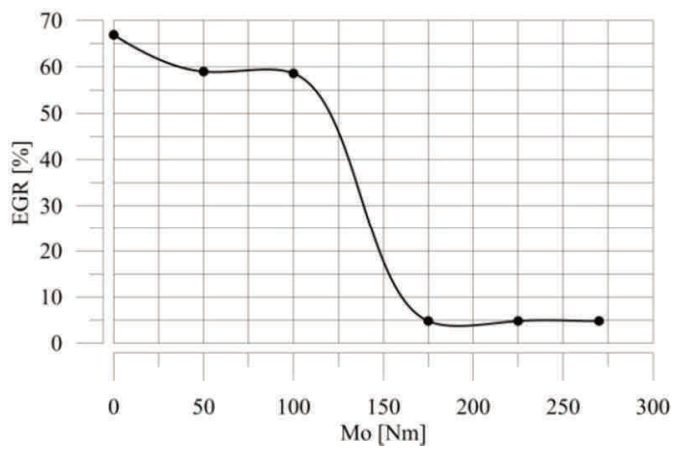

Fig. 1. Influence of engine load on factory change of opening of exhaust gas recirculation valve (EGR)

According to article CE-2017-446, the use of EGR reduces fuel consumption only at engine idle (compared to engine without EGR). At medium loadings of the engine, EGR increases hourly fuel consumption up to $20 \%$, compared to the engine without exhaust gas recirculation. In this range of engine load, EGR effect reducing the nitrogen oxide concentration in the exhaust gases up to $45 \%$ can be observed. Applying an EGR system increases the $\mathrm{CO}$ concentration by as much as $70 \%$ compared to engine operation with closed exhaust gases recirculation valve. With the exhaust gases recirculation system, an increase of exhaust smoke (by Bosch method) over 70\% was observed.
Because the comparison of the indicator graphs and the rate of heat realize in the engine cylinder operating with/without the EGR will allow a deeper study of the causal effect of exhaust gas recirculation, this paper analysis processes inside cylinder of engine working with and without EGR system.

\section{Indicator diagrams parameters}

Under the work conditions of the tested engine, the cylinder pressure is a function of the crankshaft angle, engine load and operating mode: with/without EGR. For these conditions, measurements of a number of open graphs were made and the differential characteristic, shown graphically in Fig. 2, were made. Each indicator graph is the average of 60 consecutive engine cycles, so that obtained results are representative, in spite of the natural fluctuations that result in subsequent engine cycles. It can be seen that the differential pressure in the engine cylinder working with/without EGR occurs only in the range from idle run to about 175 $\mathrm{Nm}$. Above this load, the engine controller switches the EGR system off, due to the combustion of high fuel volumes that require air not mixed with the exhaust fumes in the intake manifold. This load range obviously coincides with the course of the closure characteristics of the EGR valves shown in Fig. 1.

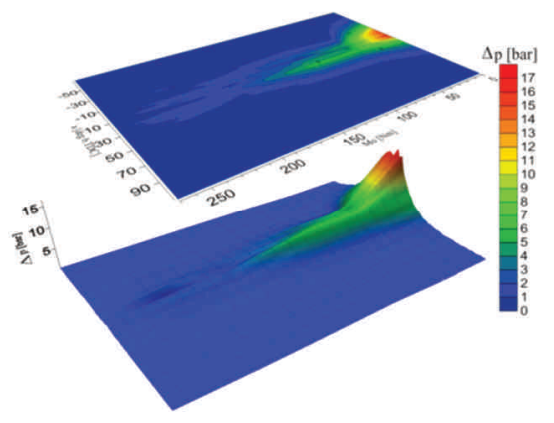

Fig. 2. Influence of crank angle of engine and engine load on pressure changing inside engine cylinder as a result of EGR valve closing 


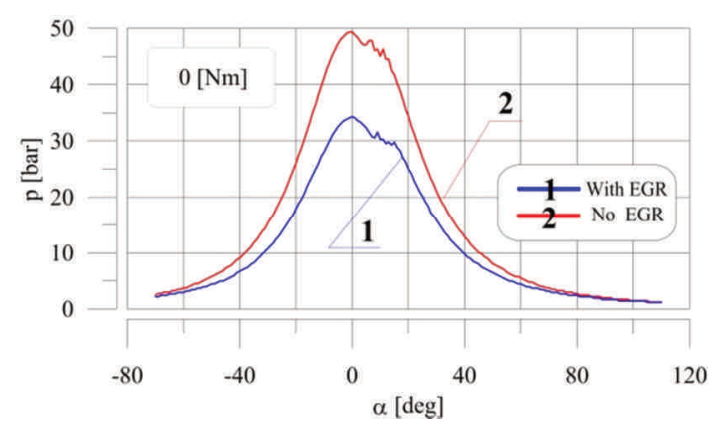

Fig. 3. Influence of the engine crank angle on the pressure inside engine cylinder for engine operating with/without EGR at torque $0 \mathrm{Nm}$

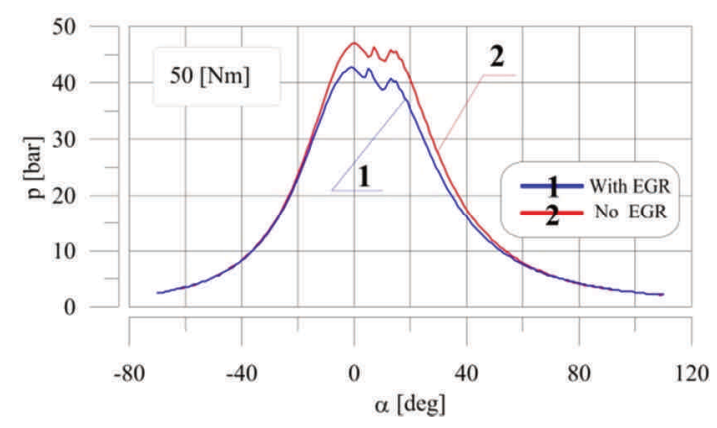

Fig. 4. Influence of the engine crank angle on the pressure inside engine cylinder for engine operating with/without EGR at torque $50 \mathrm{Nm}$

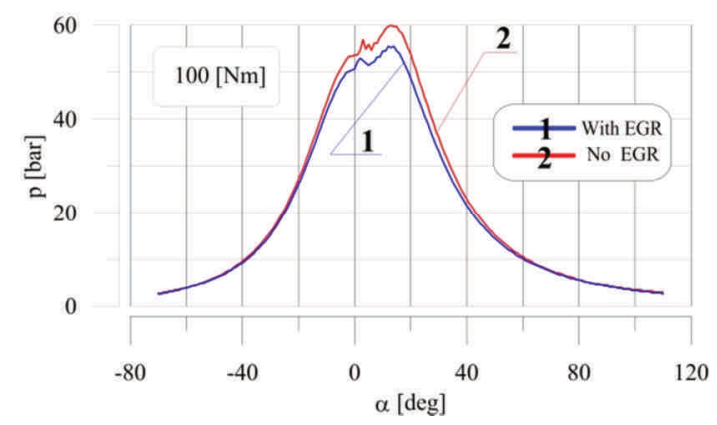

Fig. 5. Influence of the engine crank angle on the pressure inside engine cylinder for engine operating with/without EGR at torque $100 \mathrm{Nm}$

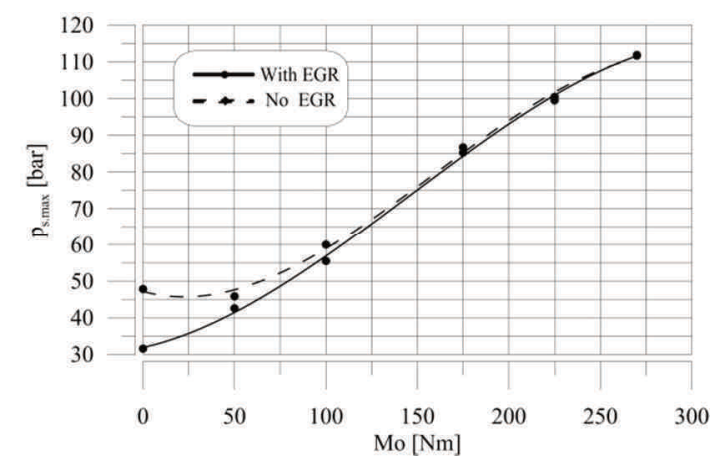

Fig. 6. Influence of the engine load on max pressure inside engine cylinder for engine operating with/without EGR

In order to analyze the pressure values in the engine cylinder working with/without EGR better, open indicator graphs were show for the 3 selected engine loads: $0 \mathrm{Nm}, 50$ $\mathrm{Nm}$ and $100 \mathrm{Nm}$, that is, in the engine work range where the EGR valve is open. This is shown in Figs 3-5. Clearly, in each of these cases, the pressure corresponding to the combustion process is significantly smaller for the engine operating with the exhaust gases recirculation. In reference to the maximum combustion pressure as a function of the engine load, this is shown in Fig. 6.

The greatest reduction in maximum combustion pressure $\mathrm{p}_{\mathrm{s}}$, max resulting in the opening of the EGR valve, occurs on the idle run of the engine. Then $\mathrm{p}_{\mathrm{s}, \max }$ for the engine operating at the factory EGR setting is about $60 \%$ lower than the pressure in the engine cylinder working without exhaust gas recirculation. Of course, the lower pressure is associated with a lower maximum combustion temperature, which is one of the main causes of the formation of $\mathrm{NO}_{\mathrm{x}}$ in the engine cylinder, and later emission of the exhaust gas. At higher engine loads (engine torque), when the engine control unit (ECU) closes the EGR valve, the difference in maximum combustion pressure in the engine cylinder working with/without EGR is lower, because it is about $10 \%$. This, however, ensures that the combustion process is carried out at lower temperatures, so that the NOx concentration in the exhaust gas is about $48 \%$ lower for the EGR engine compared to the non-EGR engine.

The $\mathrm{NO}_{\mathrm{x}}$ concentration generated in the engine cylinder is shown not as much by the average combustion temperature (associated with the combustion pressure), as maximum combustion temperature, which also depends strongly on the max. rate of combustion pressure $(\mathrm{dp} / \mathrm{d} \alpha)_{\max }$, shown in Fig.7.

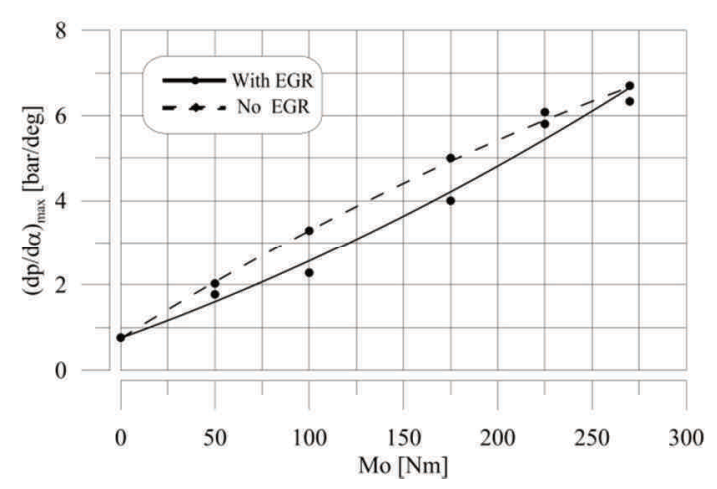

Fig. 7. Influence of the engine load on max rate of combustion pressure $(\mathrm{d} / \mathrm{d} \alpha)_{\max }$ for engine operating with/without EGR

From these data it is clear that for idle run of the engine $(\mathrm{Mo}=0 \mathrm{Nm}$ ), the difference between maximal combustion pressure in the engine cylinder working with/without EGR is $60 \%,(\mathrm{dp} / \mathrm{da})_{\max }$ is almost the same. For this reason, the $\mathrm{NO}_{\mathrm{x}}$ flue gas concentration for the engine working with/without EGR is only $50 \mathrm{ppm}$. On the other hand, for a engine load Mo $=100 \mathrm{Nm}$, at which the difference in maximum combustion pressure for an engine running with/without EGR is only $8 \%$, the difference $(\mathrm{dp} / \mathrm{d} \alpha)_{\max }$ is the highest and equals $37 \%$. At this point, the EGR system is most likely to reduce $\mathrm{NO}_{\mathrm{x}}$ concentration (Fig. 8), because it does so up to about ca. $180 \mathrm{ppm}(48 \%)$. A significant conclusion from this part of the study confirms that the reduction of $\mathrm{NO}_{\mathrm{x}}$ concentration in the exhaust gas is not only related to the reduction of the maximum combustion pressure $\mathrm{p}_{\mathrm{s}, \max }$, but also to the reduction of the maximum rise of pressure $(\mathrm{dp} / \mathrm{da})_{\max }$. 


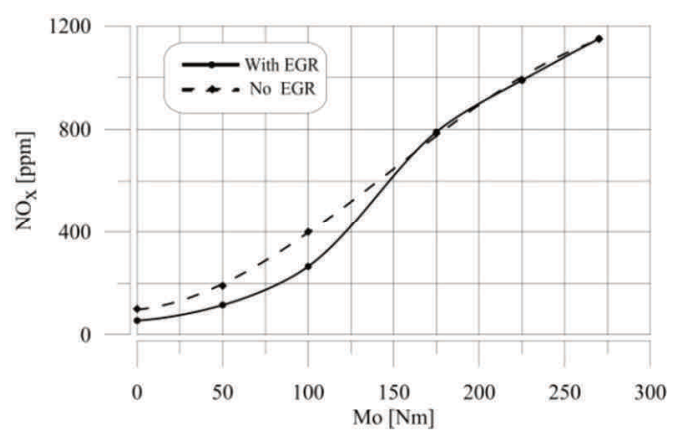

Fig. 8. Influence of the engine load on the $\mathrm{NO}_{\mathrm{x}}$ concentration in exhaust gases for engine operating with/without EGR

Using the VCDS diagnostic interface, it was found that the start of fuel injection into the engine cylinder working with the EGR system occurred slightly earlier (ca. $1 \mathrm{deg}$ ) than for an EGR - disabled engine. This may be due to the difference in the density of the working medium (chemical composition and the temperature of pure air or air mixed with the exhaust gases), which shows itself in differences in the compression pressures shown in Figs 3-5, which is the back pressure with respect to the fuel injection. In the case of an EGR engine, the early start of fuel injection, however, does not result in self-ignition delay $\left(\tau_{\mathrm{s}}\right)$, despite the beginning of the fuel injection to the pressure of the work factor that was much lower then (Figs 3-5). This is because the temperature of the air mixed with the hot exhaust, in the non-cooled EGR, is higher. Due to this physical phenomenon, the propensity for self-ignition of fuel (for an EGR engine) is greater and the start of self-ignition $\alpha_{\mathrm{ps}}$ (Fig. 10) occurs much earlier, which leads to shortening self-ignition delay $\left(\tau_{\mathrm{s}}\right)$ then - Fig. 11 .

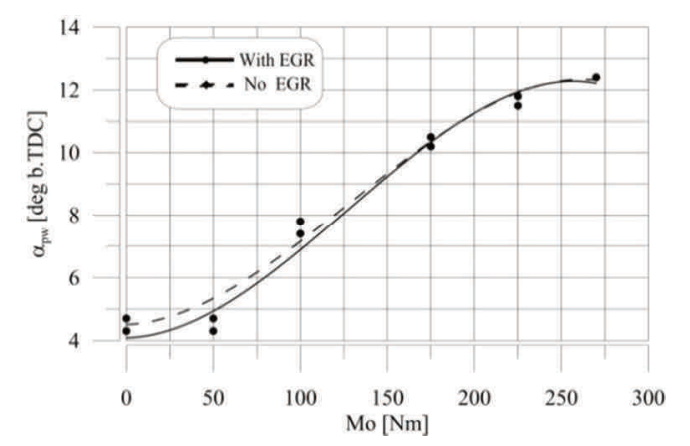

Fig. 9. Influence of the engine load on start of injection $\alpha_{\mathrm{pw}}$ for engine operating with/without EGR

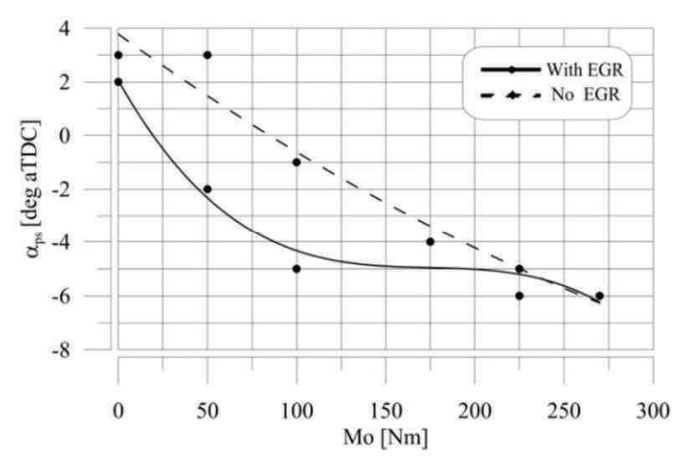

Fig. 10. Influence of the engine load on start of combustion $\alpha_{\mathrm{ps}}$ for engine operating with/without EGR

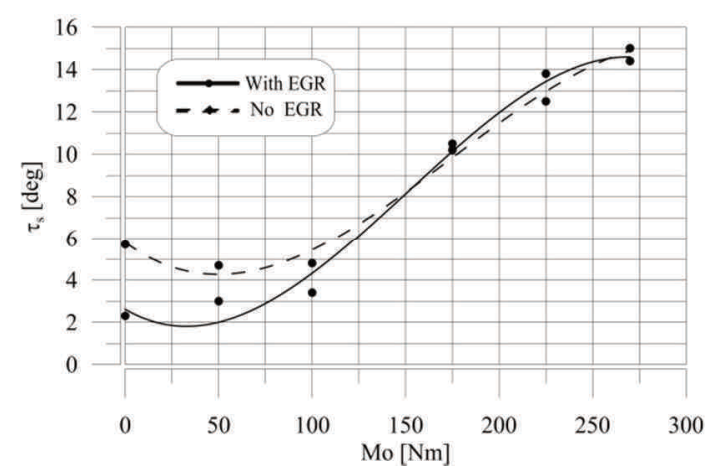

Fig. 11. Influence of the engine load delay of self-ignition $\tau_{\mathrm{s}}$ for engine operating with/without EGR

In the range of small and medium loads of the engine working with the EGR, the delay of self-ignition is smaller by about $2^{\circ} \mathrm{deg}$. Reducing the self-ignition delay reduces the time between the start of fuel injection and self-ignition, so that less fuel accumulates in the combustion chamber until self-ignition. This leads to less explosive self-ignition of fuel, which means less dynamic combustion. This results in less crankshaft system dynamic load, reduced combustion noise and lower combustion pressure rise $(\mathrm{dp} / \mathrm{d} \alpha)_{\max }$ and a lower maximum combustion temperature, resulting in a lower concentration of nitrogen oxides in the exhaust gas of the engine operating with EGR.

\section{Rate of heat release}

As the maximum temperature in the engine cylinder is a consequence of the combustion process, the effect of exhaust gas recirculation on the rate of heat release was also analyzed. This is particularly important for the analysis of the influence of structural and/or setup and/or fuel parameters on emissions of exhaust gas components. It appears that from the point of view of the composition of the exhaust gases (and also thermal efficiency of the engine), not only the value of the combustion temperature, but also its run-in time as a function of combustion time, is directly related to the distribution of the rate of heat release as a function of the angle of crankshaft rotation. The rate of heat release, with the breakdown of the kinetic and diffusion burns (Fig. 12), as commonly known; is it shows which combustion phase is responsible for the $\mathrm{NO}_{\mathrm{x}}$ concentration and which one is responsible for the PM emissions in the engine exhaust gases.

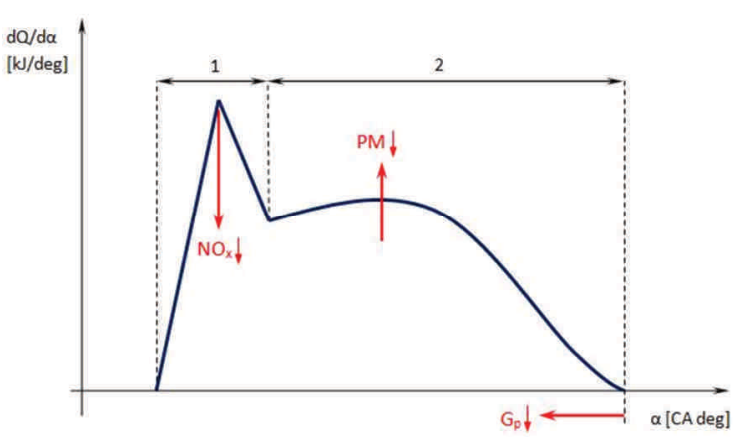

Fig. 12. Schema of the rate of heat release in a diesel engine: 1 - kinetic combustion phase 2 - diffusion combustion phase 
The function of the rate of heat release, shown in Fig. 12 , is a typical progress of CI engine in which the start of fuel injection was optimized due to the total efficiencies of the engine. This course is characterized by a high rate of kinetic combustion and a low rate of diffusion combustions. Because of the very strong reduction of emission intensity of $\mathrm{NO}_{\mathrm{x}}$ in the exhaust gases over the last 20 years, modern CI engines use a delay of start of injection (compared to the optimal state for engine total efficiency). The later start of the injection takes place into a more compressed working medium with a higher temperature, which in turn facilitates fuel spontaneous combustion, thus reducing the delay of self-ignition of fuel $\left(\tau_{\mathrm{s}}\right)$. As explained earlier, the reduction of self-ignition delay leads to less dynamic combustion, with a lower rate of heat release in the first uncontrolled combustion phase, just after the self-ignition of the fuel. There was also pilot-injection used in the engine tests, which further reduces the maximum rate of kinetic combustion. In this situation, the max rate of kinetic combustion is less than the max rate of diffusion combustion. This is advantageous in terms of reducing $\mathrm{NO}_{\mathrm{x}}$ emissions in the flue gas (by reducing the maximum combustion temperature), but it also alleviates the maximum rate of heat released in the diffusion phase of combustion. This is a disadvantage due to the Particle Matter emission and the exhaust smoke. Diesel particle matter, mainly composed of carbon blacks, is produced in the engine's cylinder, under the conditions of reduced rate of heat release in diffusion combustion. In the final balance this process increases PM emission in exhaust gases of CI engine.

Unfortunately, it is similar in the case of exhaust gas recirculation: the decrease of self-ignition $\left(\tau_{\mathrm{s}}-\right.$ Fig. 11) reduces max rate of heat release at kinetic combustion (thanks to which the emission of $\mathrm{NO}_{\mathrm{x}}$ in exhaust gases is reduced) and at the same time, rate of heat release at diffusion phase of combustion is reduced too, which significantly increases exhaust smoke and particulate matter emission.

This situation is shown in the graph of the rate of heat release as a function of the crank angle of engine working with/without EGR - Figs 13-15. In the engine range of load, where the factory EGR system works, it can be seen in the graph that the rate of heat release is lower for the engine with the open EGR valve than for the engine with EGR disabled. Thus, the EGR, which reduced the max kinetic heat release $\left(\mathrm{dQ}_{\mathrm{k}} / \mathrm{d} \alpha\right)_{\max }-$ Fig. 16, reduced the diffusion heat release $\left(\mathrm{dQ}_{\mathrm{d}} / \mathrm{d} \alpha\right)_{\max }$ as well - Fig. 17. According to the reasoning presented earlier, this unfortunately increases the emission of PM and exhaust smoke D, as shown in Fig. 18.

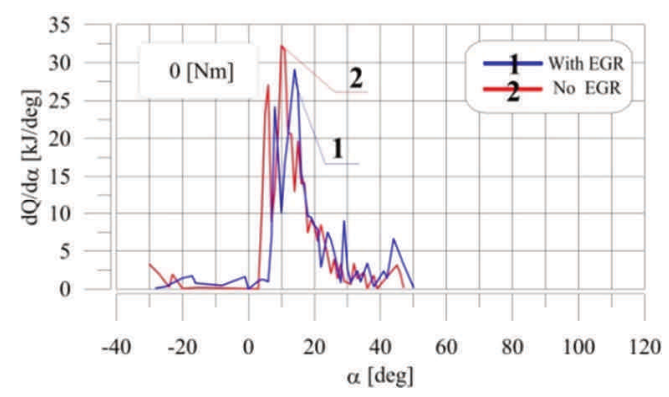

Fig. 13. Influence of the engine crank angle on the rate of heat release inside cylinder for engine operating with/without EGR at torque $0 \mathrm{Nm}$

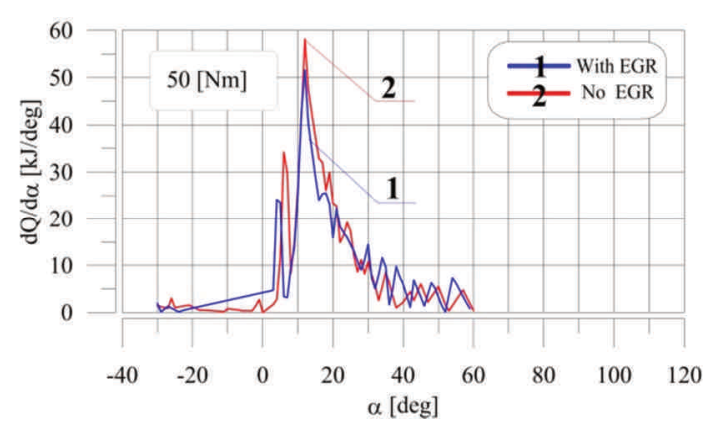

Fig. 14. Influence of the engine crank angle on the rate of heat release inside cylinder for engine operating with/without EGR at torque $50 \mathrm{Nm}$

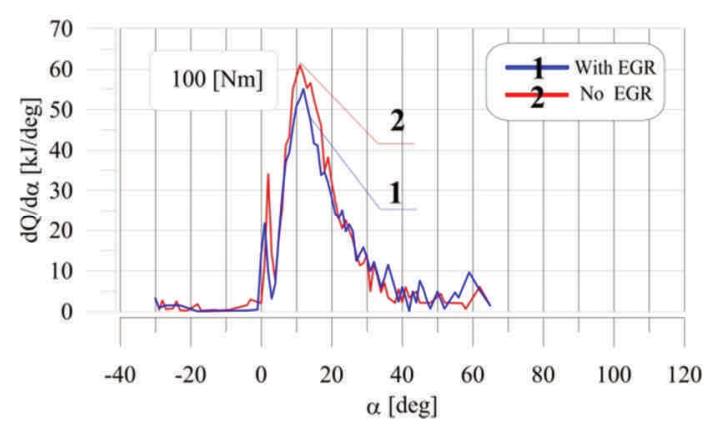

Fig. 15. Influence of the engine crank angle on the rate of heat release inside cylinder for engine operating with/without EGR at torque $100 \mathrm{Nm}$

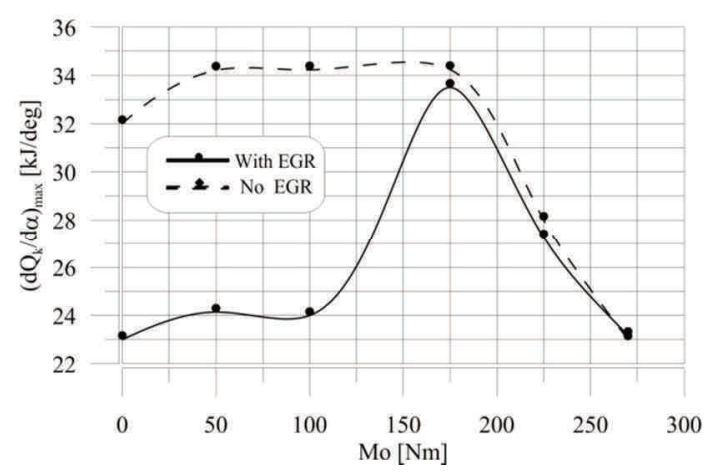

Fig. 16. Influence of the engine load on max rate of kinetic heat release $\left(d Q_{k} / d \alpha\right)_{\max }$ for engine operating with/without EGR

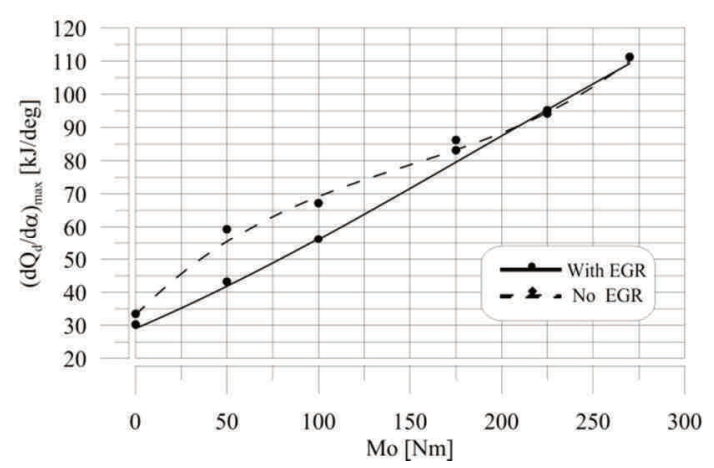

Fig. 17. Influence of the engine load on max rate of diffusion heat release $\left(\mathrm{dQ}_{\mathrm{d}} / \mathrm{d} \alpha\right)_{\max }$ for engine operating with/without EGR

As it has already been mentioned, most of the technical, structural, setup and fuel compositions, if they lead to a reduction in $\mathrm{NO}_{\mathrm{x}}$ emissions, increase $\mathrm{PM}$ emissions and vice versa. This is due to the mechanisms of formation of nitrogen oxides and particulate matter under combustion 
conditions in the cylinder of an internal combustion engine. The effect of mutual correlation, under these conditions, is schematically illustrated in Fig. 19.

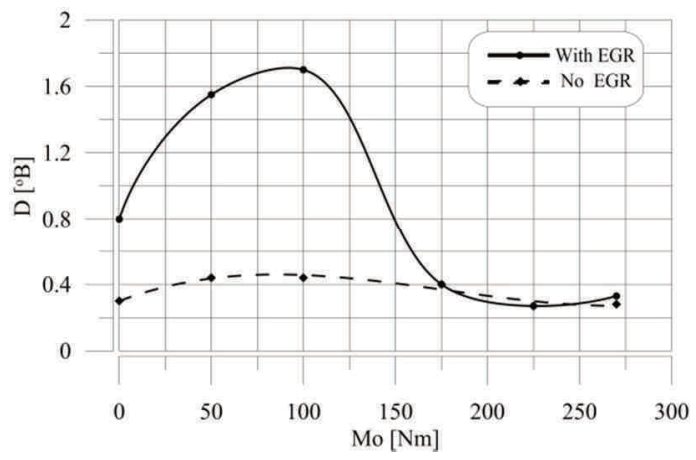

Fig. 18. Smoke exhaust $\mathrm{D}$ of diesel engine operating with/without EGR

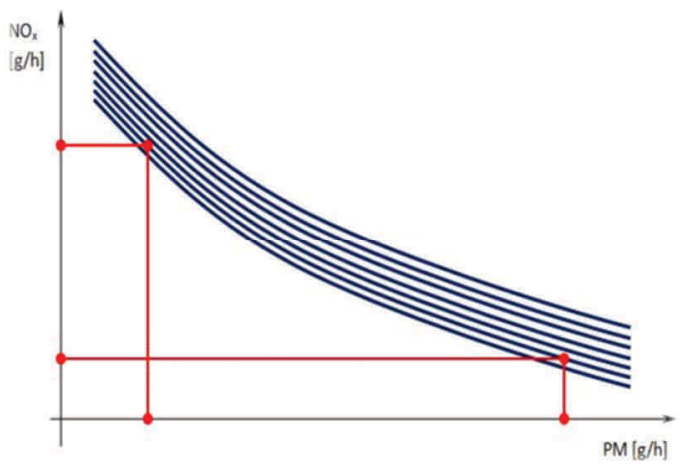

Fig. 19. The correlation between emission intensity of PM and emission intensity of nitrogen oxides emissions $\left(\mathrm{NO}_{\mathrm{x}}\right)$ in diesel engine exhaust gases

Another fact (in addition to decrease of the delay of self-ignition), which in the case of exhaust gas recirculation reduces the maximum combustion temperature, is availability of oxygen involved in the combustion process, which is smaller then. Since a part of the clean air in the intake manifold is then replaced by exhaust gases, the amount of oxygen in both the engine cylinder and exhaust gas is reducedFig. 20.

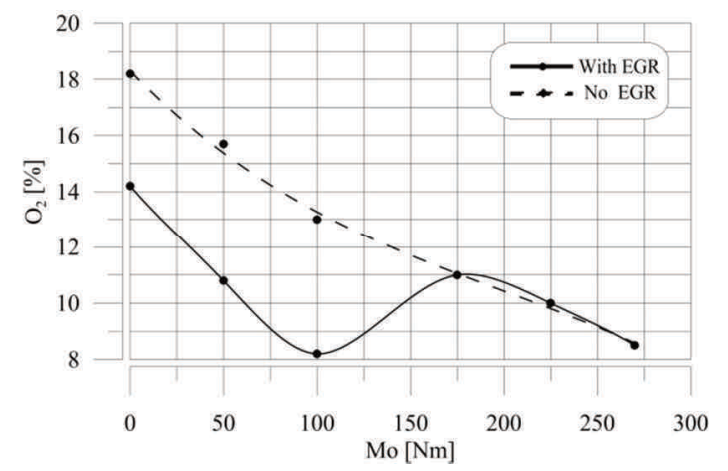

Fig. 20. Influence of the engine load on the $\mathrm{O}_{2}$ concentration in exhaust gases for engine operating with/without EGR

Another factor that, in the case of exhaust gas recirculation, reduces the combustion temperature and thereby reduces the $\mathrm{NO}_{\mathrm{x}}$ concentration in the exhaust gases is that there is much more carbon dioxide in the EGR engine cylinder than in the non-EGR engine. This is because in the delivered load of the engine cylinder there already is $\mathrm{CO}_{2}$ from the previous engine cycle (within EGR). As the amount of $\mathrm{CO}_{2}$ in the engine cylinder increases, the concentration of this compound in the engine exhaust is also increased, as illustrated in Fig. 21.

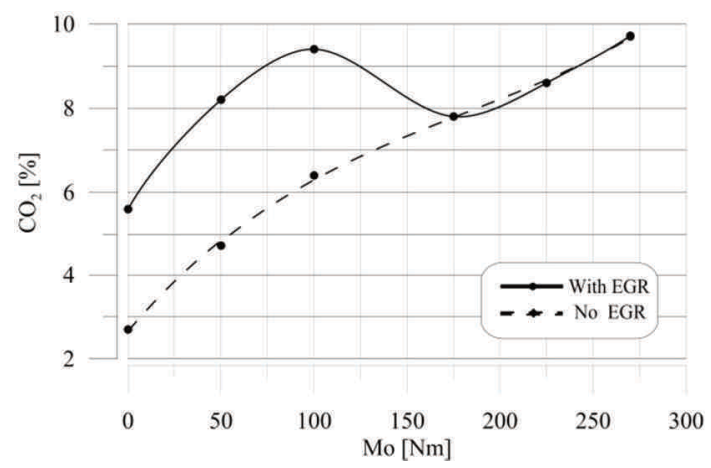

Fig. 21. Influence of the engine load on the $\mathrm{CO}_{2}$ concentration in exhaust gases for engine operating with/without EGR

The increase in $\mathrm{CO}_{2}$ concentration in the combustion process has a double effect on the reduction of the combustion temperature (and $\mathrm{NO}_{\mathrm{x}}$ in the engine exhaust):

- The process of thermal dissociation of $\mathrm{CO}_{2}$ is an endothermic process. The heat received from the working medium in the engine cylinder to decay $\mathrm{CO}_{2}$ reduces the maximum combustion temperature. From the data [1], however, it appears that heat losses due to dissociation of particles at engine operating temperatures are virtually negligible. Even at temperatures above $2000 \mathrm{~K}$ they take ca. $0.5 \%$ of the heat supplied in the fuel.

- $\mathrm{CO}_{2}$ molecules form specific thermodynamic ballast. They absorb heat (in the physical sense) that could be consumed by increasing the internal energy of the working medium, doing work, or by combining nitrogen with oxygen, and thus producing additional $\mathrm{NO}_{\mathrm{x}}$.

From the statistical treatment of the rate of heat release graphs (Figs 13-15), the end of the combustion process in the ignition engine with/without exhaust gas recirculation is also not the same. This is shown in the graph in Fig. 22.

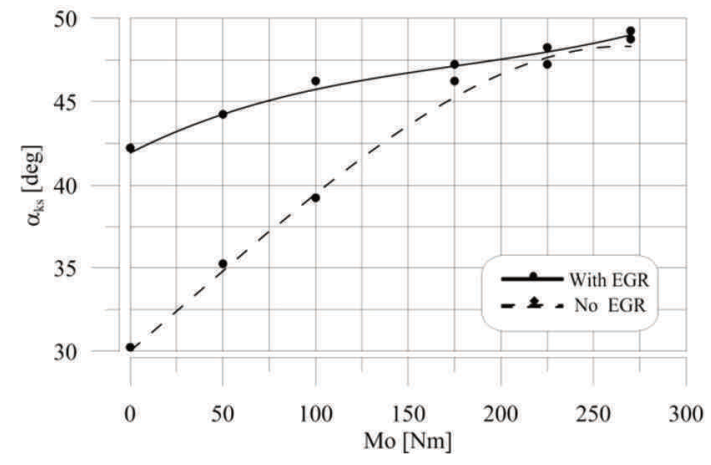

Fig. 22. Influence of the engine load on the end of combustion $\alpha_{\mathrm{ks}}$ for engine operating with/without EGR

The later end of the combustion process for an EGR engine involves practically all of the aforementioned phenomena: the availability of oxygen and the greater share of $\mathrm{CO}_{2}$ in the engine cylinder, shorter delay of self-ignition, lower rate of kinematic and diffusion heat release and more 
chronic burning, which is a more low temperature process than for the non-EGR engine.

\section{Conclusions}

The use of non-cooled exhaust gas recirculation in CI engines in relation to indicator diagrams and rates of heat release results in (compared to engines without EGR):

1. reducing the pressure of the compressed working medium in the engine cylinder (before the self-combustion of fuel),

2. reduction of maximum combustion pressure $\mathrm{p}_{\mathrm{s}, \max }$ by approx. $60 \%$ at idle run of the engine and approx. $10 \%$ at partial loads of the engine,

3. decrease in the maximum rate of combustion pressure $(\mathrm{dp} / \mathrm{d} \alpha)_{\max }$ up to $37 \%$ at $1 / 3$ of maximum engine torque. In this point of engine work decrease of $\mathrm{NO}_{\mathrm{x}}$, as a result of the EGR system action, is even $48 \%$,
4. shortening the delay of self-ignition, mainly as a physical effect of the mixing of hot exhaust gases with the air in the engine intake manifold,

5. decrease in both max rate of kinetic $\left(\mathrm{dQ}_{\mathrm{k}} / \mathrm{d} \alpha\right)_{\max }$ and diffusion $\left(\mathrm{dQ}_{\mathrm{d}} / \mathrm{d} \alpha\right)_{\max }$ heat release. Unfortunately, the reduction in the rate of diffusion combustion results in a decrease in the amount of soot burned in the engine cylinder, which in the general balance increases PM emission and exhaust smoke,

6. reduction of oxygen availability and increase of $\mathrm{CO}_{2}$ concentration in the engine cylinder significantly reduce the speed and combustion temperature, which is one of the reasons of the lower NOx emission in the engine exhaust,

7. later end of the combustion process, which also contributes to a more low-temperature combustion process.

\section{Nomenclature}

$\begin{array}{ll}\mathrm{CO}_{2} & \begin{array}{l}\text { concentration of carbon dioxides } \\ \text { compression ignition }\end{array} \\ \mathrm{CI} & \text { exhaust smoke } \\ \mathrm{E} & \text { exhaust gas recirculation } \\ \mathrm{ECU} & \\ \mathrm{Mo} & \text { engine torque } \\ \mathrm{NOx} & \text { concentration of nitrogen oxides } \\ \mathrm{O}_{2} & \text { concentration of oxygen } \\ \mathrm{PM} & \text { particulate matter } \\ \mathrm{p} & \text { pressure inside engine cylinder }\end{array}$

$\begin{array}{ll}\mathrm{p}_{\mathrm{s}, \max } & \text { maximum combustion pressure } \\ (\mathrm{dp} / \mathrm{d} \alpha)_{\max } & \text { max rate of combustion pressure } \\ \left(\mathrm{dQ} \mathrm{k}_{\mathrm{k}} / \mathrm{da}\right)_{\max } & \text { max rate of kinetic heat release } \\ \left(\mathrm{dQ} \mathrm{d}_{\mathrm{d}} / \mathrm{da}\right)_{\max } & \text { max rate of diffusion heat release } \\ \alpha & \text { crank angle } \\ \alpha_{\mathrm{pw}} & \text { start of fuel injection } \\ \alpha_{\mathrm{ps}} & \text { start of self-injection } \\ \alpha_{\mathrm{ks}} & \text { end of combustion } \\ \tau_{\mathrm{s}} & \text { delay of self-ignition }\end{array}$

\section{Bibliography}

[1] HEYWOOD, J.B. Internal combustion engine fundamentals. McGraw-Hill. Series in Mechanical Engineering. 1988.

[2] WIMMER, A., GLASER, J. Indykowanie silnika. AVL. Warszawa 2004.

[3] MERKISZ, J. Ekologiczne problemy silników spalinowych. Tom 1. Wydawnictwo Politechniki Poznańskiej. Poznań 1998.

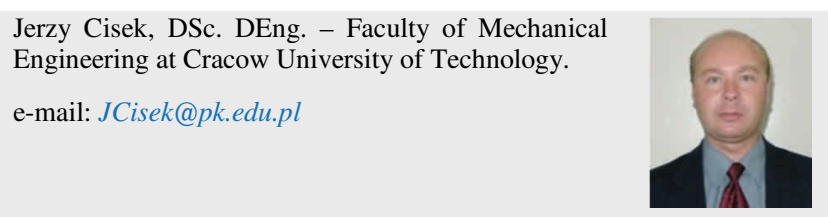

[4] MYSZKOWSKI, S. Recyrkulacja spalin w silnikach cz. 1. Dodatek techniczny do wiadomości Inter Cars S.A. 2010, 35.

[5] CIEŚLIK, W., BOROWSKI, P., PIELECHA, I. et al. System recyrkulacji spalin we współczesnych konstrukcjach silnikowych. Logistyka. 2014, 3. 